\title{
KORELASI ANTARA KUALITAS SISTEM INFORMASI PENJUALAN DENGAN KINERJA PENGGUNA
}

\author{
Raden Adi Cahyadi; Leo Nardo; Suryanto; Cecilia Sabrina \\ Information Systems Department, School of Information Systems, Binus University \\ Jl. K.H. Syahdan No. 9, Palmerah, Jakarta Barat 11480 \\ suryanto1865@yahoo.com
}

\begin{abstract}
The research aims to determine whether there is a relationship between the quality of sales information systems and user performance. The research method uses survey correlation techniques. Data are collected using a questionnaire previously calibrated to test the validity (product moment) and instrument reliability (Alpha Cronbach). The population used is users of information systems that are sales employees. There is a total sample of 20 people obtained, with Non-Probability Sampling that is saturated sampling / survey. Data analysis is performed using regression techniques of simple linear and simple correlation. Prior to analysis, test of analysis requirements need to be done, which are normality and homogeneity test. The results show a correlation coefficient of 0:51 or 51\% which means that there is a positive relationship on medium level between the Effectiveness of sales Information Systems with Users performance. The coefficient of determination is 0:26 or $26 \%$. This means that $26 \%$ of the variation in user performance can be explained by the variable Effectiveness of Sales Information Systems. Meanwhile, the remainder which is $74 \%$ consists of factors (variables), such as leadership style, work environment, salary and others. It can be concluded from this research that there is a positive correlation (relationship) at medium level which is significant between the Effectiveness of Sales Information System with User Performance, which means that the higher the level of effectiveness of Sales Information System is, the higher the level of user performance will be.
\end{abstract}

Keywords: effectiveness, sales information system, user performance

\begin{abstract}
ABSTRAK
Penelitian bertujuan untuk mengetahui apakah terdapat hubungan antara kualitas sistem informasi penjualan dengan kinerja user. Metode penelitian menggunakan survei teknik korelasional. Data dijaring menggunakan kuesioner yang sebelumnya dikalibrasi untuk menguji validitas butir (product moment) dan reliabilitas instrumen (Alpha Cronbach). Populasi yang digunakan adalah pemakai sistem informasi, yaitu karyawan bagian penjualan. Jumlah sampel sebanyak 20 orang, dengan Non Probability Sampling yaitu sampel jenuh/ survei, di mana penentuan jumlah sampel didapat. Metode analisis data menggunakan teknik regresi linear sederhana dan korelasi sederhana. Sebelum melakukan analisis perlu dilakukan uji persyaratan analisis yaitu uji normalitas dan homogenitas, Hasil penelitian menunjukkan koefisen korelasi sebesar 0.51 atau $51 \%$ yang berarti terdapat hubungan yang positif pada tingkat sedang antara Efektifitas Sistem Informasi Penjualan dengan Kinerja User. Koefisien determinasi 0.26 atau 26\%. Hal ini berarti $26 \%$ dari variasi Kinerja User dapat dijelaskan oleh variabel Efektifitas Sistem Informasi Penjualan. Sementara sisanya, yaitu sebesar 74\% terdiri dari faktor (variabel) lain, seperti Gaya Kepemimpinan, Lingkungan Kerja, Gaji dan lain-lain. Dapat disimpulkan dari penelitian ini bahwa terdapat korelasi (hubungan) yang positif pada tingkat sedang serta signifikan antara Efektifitas Sistem Informasi Penjualan dengan Kinerja User, yang artinya semakin tinggi tingkat Efektifitas Sistem Informasi Penjualan maka semakin tinggi pula tingkat Kinerja User.
\end{abstract}

Kata kunci: efektifitas, sistem informasi penjualan, kinerja pengguna 


\section{PENDAHULUAN}

Beberapa tahun terakhir ini tingkat penjualan semakin menurun, meskipun item barang yang dijual semakin banyak dan iklan mengalami kenaikan. Dugaan terjadinya penurunan karena kinerja pengguna di bagian penjualan. Penyebab kinerja pengguna disebabkan oleh tingkat kesejahteraan, manajemen perusahaan dan lingkungan, selain itu di duga menurunnya tingkat kinerja pengguna disebabkan oleh kualitas dari sistem informasi penjualan. Untuk memastikan hal tersebut maka dilakukanlah penelitian korelasional dengan tujuan untuk mengidentifikasi ada atau tidaknya korelasi antar variabel. Pada penelitian ini, sistem informasi penjualan adalah sebagai variabel bebas yang berhubungan dengan variabel terikat, yaitu kinerja user. Penelitian untuk mengetahui apakah sistem informasi penjualan benar - benar berkualitas atau tidak dan seberapa besar kontribusi sistem informasi penjualan dalam meningkatkan kinerja user. Penelitian yang dilakukan terhadap sistem yang berjalan saat ini pada PT PAS, diharapkan dapat memberikan gambaran kepada perusahaan mengenai kelebihan dan kekurangan dari sistem tersebut berdasarkan sudut pandang penggunanya.

Kualitas dari sebuah sistem informasi merupakan hal yang penting dalam mengukur kesuksesan suatu sistem informasi, sehingga kualitas sistem dan kualitas informasi merupakan komponen kualitas yang paling penting. Kepuasan user terhadap pemakai web merupakan pengaruh dari kualitas informasi dan kualitas sistem. Kesuksesan sebuah sistem dapat diukur dengan kepuasan user dalam menggunakan sistem tersebut, mungkin dari sisi kualitas sistemnya maupun informasi yang dihasilkan. Kualitas Sistem memiliki tiga dimensi yaitu access, usability, dan navigation. Kualitas informasi berpengaruh karena informasi merupakan hal yang sangat penting sehingga harus memiliki keakuratan yang tinggi. Sehingga kualitas informasi memiliki dimensi yaitu understandability, reliability, dan usefulness.

Suatu sistem informasi yang baik harus pula didukung oleh sumber daya manusia yang handal sehingga pengoperasian sistemnya dapat dilakukan secara efektif dan efisien serta dapat mencapai sasaran dan tujuan yang diharapkan oleh perusahaan. Selain itu, kinerja karyawan juga merupakan salah satu faktor penting di dalam pencapaian sasaran dan tujuan perusahaan, sehingga perusahaan juga harus memikirkan dan memperhatikan karyawannya agar dapat bekerja secara maksimal sehingga dapat memberikan nilai tambah yang bermanfaat bagi perusahaan. Kinerja pegawai merupakan hasil sinergi dari sejumlah faktor. Faktor-faktor tersebut adalah faktor lingkungan internal organisasi, faktor lingkungan eksternal organisasi dan faktor internal pegawai. Sinergi ini mempengaruhi kinerja karyawan yang kemudian mempengaruhi kinerja karyawan. Kinerja karyawan tersebut yang menentukan kinerja dari perusahaan.

PT PAS adalah perusahaan yang bergerak dalam bidang instalasi lighting. Dalam menunjang segala kegiatan mengenai data dan informasi penjualan perusahaan, maka diperlukan sistem informasi yang memadai agar penjualan barang-barang sesuai dengan yang di inginkan perusahaan.

Salah satu bentuk teknologi informasi yang dipergunakan pada PT PAS saat ini adalah sistem informasi penjualan. Sistem informasi penjualan merupakan salah satu aplikasi sistem informasi yang membantu karyawan pada perusahaan, Sistem informasi penjualan yang dikelola oleh bagian marketing.

Berdasarkan pertimbangan di atas, penelitian ini dilakukan untuk dapat mengetahui hubungan antara kualitas sistem informasi penjualan dengan kinerja user pada PT PAS. Dengan demikian, perusahaan akan dapat melakukan perubahan dan penyempurnaan pada sistemnya untuk memaksimalkan produktifitas bisnis dan kinerja karyawannya. 
Tujuan dari penelitian ini antara lain: (1) mengetahui korelasi antara kualitas sistem informasi penjualan dengan kinerja user pada PT PAS; (2) mengetahui seberapa besar kontribusi sistem informasi penjualan didalam meningkatkan kinerja user pada PT PAS.

Adapun manfaat dari penelitian ini, yang pertama bagi perusahaan yaitu: (1) memperoleh informasi mengenai besarnya korelasi antara kualitas sistem informasi penjualan dengan kinerja user pada PT PAS; (2) memperoleh informasi mengenai besarnya kontribusi sistem informasi penjualan didalam meningkatkan kinerja user pada PT PAS; (3) memperoleh informasi yang dapat menjadi masukan bagi PT PAS di dalam meningkatkan kualitas sistemnya agar dapat menunjang kinerja usernya serta dapat meningkatkan produktifitas perusahaan. Sedangkan bagi peneliti lain, hasil penelitian ini kiranya dapat dijadikan referensi dalam melakukan penelitian selanjutnya guna pengembangan penelitian di dalam topik kajian yang sama.

\section{METODE}

Kualitas sistem informasi penjualan di ukur dari kualitas sistem dan kualitas informasi, kualitas sistem mencakup adaptability, availability, reliability, response time, usability, ease of use, ease of learning, user requirements, system features, system accuracy, flexibility, sophistication, integration, and customization; kualitas informasi mencakup completeness, ease of understanding, personalization, relevance, security, availability, usability, format dan conciseness sebagaimana dijabarkan pada Tabel 1.

Tabel 1 Indikator Kualitas Sistem Informasi

\begin{tabular}{|c|c|c|c|}
\hline Author & Title & Methodology & Indicator \\
\hline $\begin{array}{l}\text { William DeLone and } \\
\text { Ephraim McLean } \\
(2003)\end{array}$ & $\begin{array}{l}\text { The DeLone and McLean } \\
\text { Model of Information } \\
\text { Systems Success: } \\
\text { A Ten-Year Update }\end{array}$ & $\begin{array}{l}\text { Empirical testing and } \\
\text { validation of the D\&M IS } \\
\text { Success Model }\end{array}$ & $\begin{array}{l}\text { Systems quality: } \\
\text { adaptability } \\
\text { availability } \\
\text { reliability } \\
\text { response time } \\
\text { usability } \\
\text { Information quality: } \\
\text { completeness } \\
\text { ease of understanding } \\
\text { personalization } \\
\text { relevance } \\
\text { security }\end{array}$ \\
\hline $\begin{array}{l}\text { Stacie Petter, } \\
\text { William DeLone and } \\
\text { Ephraim McLean (2008) }\end{array}$ & $\begin{array}{l}\text { Measuring information } \\
\text { systems success: models, } \\
\text { dimensions, measures, } \\
\text { and interrelationships }\end{array}$ & $\begin{array}{l}\text { analyze and } \\
\text { evaluate both quantitative } \\
\text { and qualitative literature }\end{array}$ & $\begin{array}{l}\text { System quality } \\
\text { ease of use } \\
\text { ease of learning } \\
\text { user requirements } \\
\text { system features } \\
\text { system accuracy } \\
\text { flexibility } \\
\text { sophistication } \\
\text { integration } \\
\text { customization } \\
\text { Information quality } \\
\text { understandability } \\
\text { availability } \\
\text { usability } \\
\text { relevance }\end{array}$ \\
\hline
\end{tabular}




\begin{tabular}{lll}
\hline Hollis Landrum, Victor & Measuring IS System Service & $\begin{array}{l}\text { assign importance } \\
\text { ratings for each of the five }\end{array}$ \\
and & Quality with & SERVPERF dimensions \\
Daniel Peak (2009) & SERVQUAL: Users' & Perceptions of Relative \\
& Importance of the Five & allocation of importance \\
& SERVPERF Dimensions & points
\end{tabular}

System quality:
ease of use
ease of learning
user requirements
system features
system accuracy
flexibility
sophistication
integration
customization
Information quality:
understandability
availability
usability
relevance
format
conciseness

\begin{tabular}{|c|c|c|c|}
\hline $\begin{array}{l}\text { Raid Moh'd Al-adaileh } \\
\text { (2009) }\end{array}$ & $\begin{array}{l}\text { An Evaluation of Information } \\
\text { Systems Success: A User } \\
\text { Perspective - the Case of } \\
\text { Jordan Telecom Group }\end{array}$ & Hypotesis testing & $\begin{array}{l}\text { System quality: } \\
\text { ease of use } \\
\text { ease of learning } \\
\text { user requirements } \\
\text { system features } \\
\text { system accuracy } \\
\text { flexibility } \\
\text { integration } \\
\text { Information quality: } \\
\text { understandability } \\
\text { availability } \\
\text { usability } \\
\text { relevance } \\
\text { format } \\
\text { conciseness }\end{array}$ \\
\hline $\begin{array}{l}\text { Rajiv Sabherwal, } \\
\text { Anand Jeyaraj, and } \\
\text { Charles Chowa (2006) }\end{array}$ & $\begin{array}{l}\text { Information System Success: } \\
\text { Individual and Organizational } \\
\text { Determinants }\end{array}$ & $\begin{array}{l}\text { Tests of Publication Bias, } \\
\text { Homogeneity Tests }\end{array}$ & $\begin{array}{l}\text { Systems quality: } \\
\text { adaptability } \\
\text { availability } \\
\text { reliability } \\
\text { response time } \\
\text { usability } \\
\text { Information quality: } \\
\text { completeness } \\
\text { ease of understanding } \\
\text { personalization } \\
\text { relevance }\end{array}$ \\
\hline
\end{tabular}

Kinerja user diukur dengan system usage, information accuracy, system reliability, user acceptance self efficacy, usability, behaviours, ease of use, usefulness sebagaimana dijabarkan pada Tabel 2. 
Tabel 2 Indikator Kinerja Pengguna

\begin{tabular}{|c|c|c|c|}
\hline Author & Title & Methodology & Indikator \\
\hline $\begin{array}{l}\text { Azzah Al-Maskari Paul } \\
\text { Clough Mark Sanderson } \\
(2008)\end{array}$ & $\begin{array}{l}\text { Users' Effectiveness and } \\
\text { Satisfaction for Image } \\
\text { Retrieval }\end{array}$ & $\begin{array}{l}\text { analysis of variance } \\
(A N O V A)\end{array}$ & $\begin{array}{l}\text { Usefulness of the results, } \\
\text { satisfaction with the } \\
\text { accuracy (efficiency) and } \\
\text { coverage (completeness) of } \\
\text { the results. }\end{array}$ \\
\hline $\begin{array}{l}\text { Raid Moh'd Al-adaileh } \\
(2009)\end{array}$ & $\begin{array}{l}\text { An Evaluation of } \\
\text { Information Systems } \\
\text { Success: A User } \\
\text { Perspective - the Case of } \\
\text { Jordan Telecom Group }\end{array}$ & $\begin{array}{l}\text { validity testing } \\
\text { reliability testing, and } \\
\text { Hypotesis testing }\end{array}$ & $\begin{array}{l}\text { user's technical capabilities } \\
\text { and management support }\end{array}$ \\
\hline $\begin{array}{l}\text { Mohd Afandi Md Amin } \\
\text { (2010) }\end{array}$ & $\begin{array}{l}\text { Measuring the } \\
\text { performance of Customs } \\
\text { Information Systems } \\
\text { (CIS) in Malaysia }\end{array}$ & $\begin{array}{l}\text { balanced scorecard } \\
\text { approach (BSC), } \\
\text { key performance } \\
\text { indicators (KPI), } \\
\text { the economic value- } \\
\text { added approach } \\
\text { (EVA), } \\
\text { activity-based costing } \\
\text { (ABC) and } \\
\text { total quality } \\
\text { management }(T Q M)\end{array}$ & $\begin{array}{l}\text { User satisfaction: } \\
\text { system usage } \\
\text { information accuracy } \\
\text { system reliability } \\
\text { User acceptance } \\
\text { self-efficacy } \\
\text { usability } \\
\text { behaviours } \\
\text { ease of use } \\
\text { usefulness }\end{array}$ \\
\hline Majid Ramezan (2005) & $\begin{array}{l}\text { Measuring the } \\
\text { effectiveness of human } \\
\text { resource information } \\
\text { systems in national } \\
\text { Iranian oil company }\end{array}$ & $\begin{array}{l}\text { Validity testing and } \\
\text { reliability testing }\end{array}$ & $\begin{array}{l}\text { ease of accessibility to } \\
\text { systems } \\
\text { relevance of information } \\
\text { high accuracy } \\
\text { precision } \\
\text { speed }\end{array}$ \\
\hline
\end{tabular}

Berikut ini korelasi antara kualitas sistem informasi dengan kinerja pengguna (Tabel 3):

Tabel 3 Korelasi antara Kualitas Sistem Informasi dengan Kinerja Pengguna

\begin{tabular}{|c|c|c|c|}
\hline Author & Title & Methodology & Finding \\
\hline $\begin{array}{l}\text { William DeLone and } \\
\text { Ephraim McLean } \\
\text { (2003) }\end{array}$ & $\begin{array}{l}\text { The DeLone and McLean } \\
\text { Model of Information } \\
\text { Systems Success: } \\
\text { A Ten-Year Update }\end{array}$ & $\begin{array}{l}\text { Empirical testing and } \\
\text { validation of the D\&M IS } \\
\text { Success Model }\end{array}$ & $\begin{array}{l}\text { Terdapat korelasi antara sistem } \\
\text { informasi penjualan dengan } \\
\text { kinerja } u \text { ser; } \\
\text { Terdapat pengaruh yang } \\
\text { signifikansi antara sistem } \\
\text { informasi penjualan dengan } \\
\text { kinerja } u \text { ser }\end{array}$ \\
\hline $\begin{array}{l}\text { Stacie Petter, } \\
\text { William DeLone and } \\
\text { Ephraim McLean } \\
(2008)\end{array}$ & $\begin{array}{l}\text { Measuring information } \\
\text { systems success: models, } \\
\text { dimensions, measures, } \\
\text { and interrelationships }\end{array}$ & $\begin{array}{l}\text { analyze and } \\
\text { evaluate both } \\
\text { quantitative and } \\
\text { qualitative literature }\end{array}$ & $\begin{array}{l}\text { Terdapat korelasi antara sistem } \\
\text { informasi penjualan dengan } \\
\text { kinerja } u \text { ser; } \\
\text { Terdapat pengaruh yang } \\
\text { signifikansi antara sistem } \\
\text { informasi penjualan dengan } \\
\text { kinerja } u s e r\end{array}$ \\
\hline
\end{tabular}




$\begin{array}{llll}\text { Hollis Landrum, Victor } & \text { Measuring IS System Service } & \text { assign importance } & \text {. Terdapat korelasi antara sistem } \\ \text { Prybutok, Xiaoni } & \text { Quality with } & \text { ratings for each of the } & \text { informasi penjualan dengan } \\ \text { Zhang, and } & \text { SERVQUAL: Users } & \text { five SERVPERF } & \text { kinerja user; } \\ \text { Daniel Peak (2009) } & \text { Perceptions of Relative } & \text { dimensions that differ } & \text {. Terdapat pengaruh yang } \\ & \text { Importance of the Five } & \text { from their allocation of } & \text { signifikansi antara sistem } \\ & \text { SERVPERF Dimensions } & \text { importance } & \text { informasi penjualan dengan } \\ & & \text { points } & \text { kinerja user }\end{array}$

Penelitian ini dilakukan di PT PAS. Total responden 20 orang pengguna sistem informasi penjualan. Semua kuisioner yang disebarkan telah diisi lengkap, Hasil penyebaran kuisioner tahap 1 digunakan untuk menguji validitas dan reliabilitas. Berdasarkan pengujian validitas dengan metode Pearson di peroleh hasil sebagai berikut (Table 4):

Tabel 4 Kisi-Kisi Sebaran Instrumen Penelitian

\begin{tabular}{|c|c|c|c|c|c|}
\hline No. & $\begin{array}{l}\text { Variabel } \\
\text { Penelitian }\end{array}$ & $\begin{array}{c}\text { Sebelum Uji } \\
\text { Coba }\end{array}$ & $\begin{array}{c}\text { Sesudah Uji } \\
\text { Coba }\end{array}$ & $\begin{array}{c}\text { Jumlah Butir } \\
\text { Sebelum Uji } \\
\text { Coba }\end{array}$ & $\begin{array}{c}\text { Jumlah Butir } \\
\text { Sesudah Uji } \\
\text { Coba }\end{array}$ \\
\hline 1 & $\begin{array}{l}\text { Kualitas Sistem } \\
\text { Informasi } \\
\text { penjualan }\end{array}$ & $\begin{array}{l}1,2,3,4,5,6,7, \\
8,9,10,11,12, \\
13,14,15,16, \\
17,18,19,20, \\
21,22,23,24, \\
25\end{array}$ & $\begin{array}{l}1,2,3,4,5,7,8 \\
9,10,11,12,13, \\
14,15,16,17 \\
19,20,23,24\end{array}$ & 25 & 20 \\
\hline 2 & Kinerja User & $\begin{array}{l}26,27,28,29, \\
30,31,32,33, \\
34,35,36,37, \\
38\end{array}$ & $\begin{array}{l}26,27,30,31 \\
33,35,36,37,38\end{array}$ & 13 & 9 \\
\hline & & Jumlah & & 39 & 29 \\
\hline
\end{tabular}

Hasil pengujian reliabilitas untuk variabel kualitas sistem informasi penjualan dengan metode Alphacronbach adalah 0,87 sedangkan hasil pengujian reliabilitas variabel kinerja user. Kuisioner tersebut dinyatakan valid dan reliabel. Metode pengumpulan data dengan penyebaran kuisioner kepada pengguna sistem informasi penjualan pada PT PAS, metode pengolahan data dengan menggunakan SPSS versi 18,0. Metode analisi data dengan menggunakan statistik deskriptif untuk menggambarkan profil responden, dan statistik inferensial untuk menguji hipotesis.

\section{HASIL DAN PEMBAHASAN}

Kuisioner yang telah reliabel disebar kembali ke 20 responden hasil dari pengisian kuisioner dapat di ringkas seperti yang disajikan pada Tabel 5: 
Tabel 5 Rangkuman Deskripsi Data Distribusi Frekuensi

\begin{tabular}{rlrr}
\hline No. & \multicolumn{1}{c}{ Perhitungan } & $\begin{array}{c}\text { Kualitas Sistem } \\
\text { Informasi Penjualan }\end{array}$ & Kinerja Pengguna \\
\hline 1. & Skor Terendah & 20 & 8 \\
2. & Skor Tertinggi & 100 & 45 \\
3. & Rentang Skor & 80 & 37 \\
4. & Data Terkecil & 74 & 31 \\
5. & Data Terbesar & 87 & 43 \\
6. & Rentang Data & 20 & 10 \\
7. & Jumlah & 1586 & 742 \\
8. & Mean & 79,30 & 37,10 \\
9. & Median & 79 & 37,5 \\
10. & Modus & 81 & 39 \\
11. & Varians & 12,011 & 8,411 \\
12. & Standar Deviasi & 3,466 & 2,900 \\
\hline
\end{tabular}

Pengujian persyaratan analisis meliputi pengujian normalitas, homogenitas, linierlitas dan signifikansi. Hasil pengujian normalitas dengan metode liliefors menunjukkan Lhitung sebesar 0,0865 di mana Ltabel sebesar 0,1900 karena Lhit $<$ Ltabel sehingga data berdistribusi manual.

Hasil pengujian homogenitas dengan metode Chisquare menunjukan $x^{2}$ hitung sebesar 4,59 di mana $x^{2}$ tabel sebesar 12,592 karena Lhitung $<$ Ltabel, datanya homogen.

\section{Pengujian Hipotesis}

Rumusan Hipotesis penelitian adalah:

H0: ada hubungan yang signifikansi antara kualitas system informasi penjualan dengan kinerja user. $\mathrm{H} 1$ : tidak ada hubungan yang signifikansi antara kualitas system informasi penjulan degan kinerja user.

Hasil analisis dapat dilihat pada Tabel 6.

Tabel 6 Analisis Varians untuk Pengujian Signifikansi dan Linearitas Persamaan Regresi Ŷ $=3,253+0,427 X$

\begin{tabular}{lrrrrr}
\hline \multicolumn{1}{c}{ Sumber } & dk & \multicolumn{1}{c}{ JK } & KT & F hit. & $\begin{array}{c}\text { F tab } \\
(\mathbf{0 . 0 5})\end{array}$ \\
\hline variasi & & & & & \\
Total & 20 & 27688 & & & \\
Koefisien a & 1 & 27528,20 & 27528,20 & & \\
Koefisien b/a & 1 & 41,57 & 41,57 & & \\
Sisa & 18 & 118,23 & 6,57 & 6,33 & 4,41 \\
Tuna cocok & 5 & 9,89 & 1,98 & & \\
Galat & 13 & 108,33 & 8,33 & 0,24 & 2,77 \\
\hline
\end{tabular}

Dari hasil pengujian tersebut menunjukkan Fhitung sebesar 6,33 dari tabel $f$ menunjukkan 4,41. Fhitung $>$ Ftabel maka diterima $\mathrm{H} 0$ yang berarti ada hubungan yang signifikansi anatara kualitas 
system informasi penjualan dengan kinerja user. Hasil pengujian menunjukkan Fhitung tuna cocok sebesar 0,24 dengan Ftabel $=2,77$. Fhitung $<$ Ftabel maka persamaan regresi linier, persamaan regresi dengan $\mathrm{Y}=3,253+0,427 \mathrm{X}$ menunjukkan setiap kenaikan 1 satuan kualitas system informasi penjualan akan menaikkan kinerja user sebesar 0,427.

Koefisien korelasi sebesar 0,51 dengan kofisiean determinasi sebesar 0,26 atau $26 \%$ berarti variable kinerja user dipengaruhui oleh kualitas system informasi penjualan sebesar $26 \%$ sisany $74 \%$ dipengaruhi oleh faktor-faktor lain.

\section{PENUTUP}

Berdasarkan hasil analisis regresi linear sederhana dan korelasi sederhana, dapat disimpulkan bahwa terdapat korelasi yang lemah antara kualitas sistem informasi penjualan dengan kinerja user, sehingga hipotesis korelasi $\mathrm{H}_{\mathrm{a}}$ diterima yaitu terdapat hubungan yang positif antara kualitas sistem informasi penjualan dengan kinerja user. Angka korelasi antara kualitas sistem informasi penjualan dengan kinerja user menghasilkan angka $\left(\mathrm{r}^{2}\right)=0,26$. Hal ini menunjukkan hubungan yang lemah antara kualitas sistem informasi penjualan dengan kinerja user. Kelemahan hubungan tersebut didapat melalui hasil pengujian signifikansi korelasi sebesar Fhitung - 6,33 > Ftabel - 4,41 adalah signifikan. Hal ini menunjukkan bahwa tingkat kualitas sistem informasi penjualan tidak berpengaruh besar terhadap kinerja user secara keseluruhan.

Persamaan regresi $\hat{Y}=3,253+0,427 X$ memberi arti bahwa setiap peningkatan satu satuan dari skor kualitas sistem informasi penjualan akan berdampak pada kenaikan skor kinerja user sebesar 0,427 pada konstanta 3,253.

Koefisien determinasi $\left(\mathrm{r}^{2}\right)$ sebesar 0,26 atau $26 \%$ yang merupakan pengkuadratan dari $\mathrm{r}$ atau koefisien korelasi sebesar 0,51. Di mana $26 \%$ dari variasi yang terjadi dalam kinerja user dapat dijelaskan oleh variabel kualitas sistem informasi penjualan melalui persamaan regresi $\hat{Y}=3,253+$ $0,427 \mathrm{X}$ atau dapat diartikan bahwa kualitas sistem informasi penjualan memberikan kontribusi sebesar $26 \%$ terhadap kinerja user sedangkan $74 \%(100 \%$ - 26\%) dipengaruhi oleh faktor lain seperti faktor lingkungan internal organisasi yang lainnya yaitu sistem manajemen, kepeminpinan, kebijakan organisasi, iklim organisasi, strategi organisasi, budaya organisasi, kemudian faktor lingkungan eksternal organisasi yaitu kehidupan ekonomi, politik, sosial, budaya dan kompetitor, serta faktor internal karyawan itu sendiri yaitu keadaan psikologi, sifat pribadi, dan pengalaman kerja.

Pada uji signifikansi (Fhitung), menunjukkan angka 6,33 > dari Ftabel sebesar 4,41 dengan taraf signifikansi $0,05(5 \%)$. Hal ini berarti penolakan terhadap $\mathrm{H}_{0}$ dan menerima $\mathrm{H}_{1}$ atau koefisien regresi signifikan. Dengan demikian, dapat disimpulkan bahwa variabel kualitas sistem informasi penjualan berpengaruh pada kinerja user.

\section{DAFTAR PUSTAKA}

DeLone, William H., and Ephraim, R.McLean. (2003). Model of Information Systems Success: A TenYear Update. Diakses dari http://www.asiaa.sinica.edu.tw/ ccchiang/GILIS/LIS/p9Delone.pdf. 
Landrum, H., Prybutok, V., Zhang, X., and Peak, D. (2009). Measuring IS System Service Quality with SERVQUAL: Users' Perceptions of Relative Importance of the Five SERVPERF Dimensions. Diakses dari http://inform.nu/Articles/Vol12/ISJv12p017-035Landrum232.pdf.

Petter, Stacie., DeLone, William., and McLean, Ephraim. (2008). Measuring Information Systems Success: Models, Dimensions, Measures, and Interrelationships. Diakses dari http://mtweb.mtsu.edu/jclark/698/articles/measuring\%20information\%20systems\%20success $\% 20$ models\%20dimensions\%20measures\%20and\%20interrelationships.pdf.

Ramezan, Majid. (2010). Measuring The Effectiveness Human Source Information Systems in National Iranian Oil Company. Diakses dari http://www.ijms.ir/pg/02/ijms0207.pdf. 